Available online at GSC Online Press Directory

GSC Biological and Pharmaceutical Sciences

e-ISSN: 2581-3250, CODEN (USA): GBPSC2

Journal homepage: https://www.gsconlinepress.com/journals/gscbps

(RESEARCH ARTICLE)

\title{
Prevalence of HIV among women attending selected hospitals in Minna, Niger state, Nigeria
}

\author{
Adeoye Racheal Adepeju ${ }^{2}$, Garba Samuel Alimi ${ }^{2}$, Galadima Musa ${ }^{2}$, Ossamulu Ifeanyi Famous ${ }^{1}$ and \\ Ariyeloye Stephen Damola $1{ }^{*}$ \\ ${ }^{1}$ Department of Biochemistry, Federal University of Technology, P.M.B. 65, Minna, Nigeria. \\ 2 Department of Microbiology, Federal University of Technology, P.M.B. 65, Minna, Nigeria.
}

Publication history: Received on 23 August 2019; revised on 10 October 2019; accepted on 15 October 2019

Article DOI: https://doi.org/10.30574/gscbps.2019.9.1.0160

\begin{abstract}
Over a nine-month period, the prevalence of HIV among women attending selected Hospitals (Dr Musa Inuwa, General, Clinic A, IBB, and Clinic B hospitals) in Minna was studied. A total of 500 patients were selected and their blood samples collected. Questionnaires were used to gather relevant data on sampled patients. Presence of antibodies to HIV 1 and 2 was determined using Determin HIV 1/2 kit. Of the 500 samples, 408 tested negative while 92 tested positive, translating to a prevalence rate of $18.4 \%$. The age group $25-34$ years had the highest number of cases under HIV positive pregnant women (67.7\%). Except for location, there was a significant association between HIV/ pregnancy status and the various factors. Government and non-government organizations are advised to intensify efforts to arrest the situation.
\end{abstract}

Keywords: HIV (Human Immunodeficiency Virus); AIDS (Acquired immunodeficiency syndrome); Prevalence; Pregnancy

\section{Introduction}

Over the last thirty years, more than 25 million people have lost their lives to HIV [1]; presently, over 36 million others, about half being women of reproductive age, are living with the deadly virus [2]. Also, mother-to-child infection puts some 1 million children in the list of the infected. Overall, the data sits largely in the developing countries: over $90 \%$ of infected children and two-third of adults are in Africa (Centre for Disease Control and prevention [3]. The Human Immunodeficiency Virus (HIV), a retrovirus of the Lentivirus subgroup, which is responsible for HIV infection and the subsequent Acquired Immunodeficiency Syndrome (AIDS) [4] remains- as the data above suggest- a serious threat to public health and the economy.

The design of any serious combative measure against HIV necessarily require reliable knowledge of the factors favoring its continued spread. Mother-to-child transmission prevention programs have been a major source of data used to infer the risk factors and prevalence of the infection in majority of the African countries, the data being from the women participating in such programs. Results gotten from such studies may be generalized on the rest of the women in the populace which are in the reproductive-age bracket, given the far reach of antenatal services and the comparatively high background fertility.

[5] Pointed out ways of reducing the transmission of the virus, including enabling of women to optimally maintain their health using their test results, and the training of staff, alongside provision of equipment, to disallow nosocomial transmission of the virus and other deadly pathogens. Mother-to-child transmission can be combated by HIV counseling,

\footnotetext{
${ }^{*}$ Corresponding author

E-mail address: Ariyeloye@gmail.com
} 
conducting tests, anti-retroviral (ARV) prophylaxis, safer delivery and safer infant feeding practices. It is very important that people, including pregnant women, make themselves available for counseling and tests, if HIV/AIDS is to be effectively managed in the general population. The survival and health of both mothers and children could be ensured by screening expecting women to access ARV drugs; this cut chance of infecting new-borns with the virus slim and improve the mothers' quality of life [3].Documented data on the prevalence of human immunodeficiency virus (HIV) infection among women, whether pregnant or not, in Minna, Niger State Nigeria is lacking, making this study of importance.

\section{Material and methods}

\subsection{Study area}

This research was conducted in the following, all of which are in Minna: Clinic A, Dr Musa Inuwa Hospital, General Hospital, Clinic B, IBB Specialist Hospital. Minna, the capital city of Niger State Nigeria, with a population of 3,950,249 and land mass of 29.484sqm, lies at latitude of 3.20' and longitude 8 and 11.3', roughly 150 km away from Abuja. It is occupied majorly by the Nupes, Hausas and Gbagyis [6].

\subsection{Study population}

A total number of five hundred (500) volunteers, all women, were the subjects of the study. They were all attendants of General Out Patient Department (GOPD) and Obstetrical and Gynecology (O \& G) departments of the five hospitals used for the study, namely Clinic A, Dr Musa Inuwa Hospital, General Hospital, Clinic B, IBB Specialist Hospital Minna, and were engaged for this study from January to September, 2016. Eligible patients were administered questionnaires to collect data on their HIV and socio-demographic status. Blood samples were collected from the hospitals in the following distribution: 50 from Clinic A, 100 from Dr Musa Inuwa Hospital, 200 from General Hospital, 50 from Clinic A, and 100 from IBB Specialist Hospital.

\subsection{Sample size formula}

Sample size was estimated using Krejcie Morgan method as used by [7].

$\mathrm{n}=\underline{\mathrm{T}^{2} \mathrm{P}(1-\mathrm{P})^{2}}$

$\mathrm{M}^{2}$

Where $\mathrm{N}=$ sample size

$\mathrm{T}=$ the standard normal deviation at 1.96

$\mathrm{P}=$ Prevalence of disease, 0.24 (NGSACA)

$\mathrm{M}=$ Marginal tolerable error at 0.05

$\mathrm{N}=\underline{1.962 \times 0.24(1-0.24)}$

$0.05^{2}$

$\mathrm{N}=\underline{3.8416 \times 0.24 \times 0.76}$

0.0025

$\mathrm{N}=280.28$

Thus, the sample size was computed to be 280 . However, a total of 500 subjects were used in this study.

\subsection{Blood Sample Collection}

Vein puncture technique [8] was employed for blood sample collection. The upper arm of the subject was tied with soft tubing tourniquet; methylated spirit was used to sterilize the puncture site; vein puncture was made with needle attached to a $5 \mathrm{ml}$ syringe and syringe full of blood was collected. The $5 \mathrm{ml}$ blood was transferred into a labeled ethylene-diamine - tetra- acetic acid (EDTA) container to prevent clothing. 


\subsection{Screening for HIV}

This was done using Determine HIV1/2 kit (Abbot Laboratories II, USA). Sterile micropipettes were used to transfer 2 drops of plasma to the test pad. The test was given fifteen minute to develop after the plasma migrated to the patient and control lines. It was read at the end of that time. All samples that came out positive were subjected to further screening using Unigold and statpak HIV1 / 2. A third assay (Statpak HIV1/2) was used to confirm results discordant between Determine HIV 1/2 and Unigold HIV1/2. This was in accordance with the National algorithm for HIV screening.

\subsection{Result Interpretation}

Positive results were inferred from presence of red lines in both patient window and control window; negative was inferred from just one red line being in the control window only. A test result is invalid if no red line appeared on the control window and patient window.

\subsection{Statistical Analysis}

Statistical Package for Social Science (SPSS) was used for the analysis. Data obtained from the study were subjected to chi square to compare and test for relationship between the means at $\mathrm{p}<0.05$.

\section{Results}

\subsection{Seroprevalence of HIV}

The seroprevalence of HIV among women from the five hospitals in Minna is shown in Table 1. Of the samples tested, $81.6 \%$ ( 408 out of 500) came negative while the rest- 18.4\% (92 out of 500) were positive. The highest occurrence of positive tests were from General Hospital samples (57), while the lowest was from Clinic A, Minna.

Table 1 The Prevalence of HIV in the Study Area

\begin{tabular}{llll}
\hline Study area & Total No. Screened & Total No. Positive & Total No. Negative \\
\hline G. H & 200 & 57 & 143 \\
IBB & 100 & 23 & 77 \\
M. I. W & 100 & 9 & 91 \\
Clinic B & 50 & 2 & 48 \\
Clinic A & 50 & 1 & 49 \\
Total & 500 & 92 & 408 \\
Percentage (\%) & & $18.4 \%$ & $81.6 \%$
\end{tabular}

G.H.M - General Hospital Minna; IBB - Ibrahim Badamasi Babangida Hospital Minna; M.I - Dr. Musa Inuwa Hospital Wushishi Estate Minna; C.B Clinic B; C.A - Clinic A

\subsection{Antiretroviral therapy}

Table 2 The Total Number of HIV Positive Cases

\begin{tabular}{llll}
\hline \multicolumn{4}{c}{ ART management } \\
\hline \multirow{2}{*}{ Pregnant women } & $25(80.6)$ & Not on ART (\%) & Total \\
Not pregnant women & $42(68.9)$ & $6(19.4)$ & 31 \\
Total & $67(72.8)$ & $19(31.1)$ & 61 \\
\hline \multicolumn{4}{c}{$\mathrm{x}^{2}=1.444, \mathrm{p}=0.322$} \\
\multicolumn{4}{c}{ On ART - On Antiretroviral Therapy, Not on ART - Not on Antiretroviral Therapy }
\end{tabular}


Statistics for infected pregnant and non-pregnant women that undergo ART (Antiretroviral Therapy) management is presented in Table $2.80 .6 \%$ of pregnant women (25 out of 31) were undergoing ART, while $19.4 \%$ (6 out of 31) were not. Of the nonpregant women, $68.9 \%$ (42 out of 61) were on ART while $31.1 \%$ (19 out of 61) were not. From the chi square analysis, it can be concluded that there was no significant $(\chi 2=1.444, p=0.322)$ association between pregnancy status and ART management.

\subsection{Seroprevalence of HIV among pregnant and non-pregnant women in relation to age}

Table 3 shows the seroprevalence of HIV among pregnant and non-pregnant women in relation to age. Among pregnant women, the highest occurrence of HIV positive is recorded for women in the 25-34 age bracket. No pregnant woman above 55years of age, hence zero record for both HIV-positive and HIV-negative pregnant women above 55years. Among non-pregnant women, the highest occurrence of HIV positive is recorded for women in the 35-44 age bracket. Women above 55years also had least occurrence $(1.6 \%)$. The chi square analysis $(\chi 2=68.621, \mathrm{p}=0.000)$ revealed a significant relationship ( $\mathrm{p}<0.05)$ between $\mathrm{HIV} /$ pregnancy status and age. Therefore, age may be a predisposing factor to HIV infection for women, whether they are pregnant or not.

Table 3 Relationship between HIV/Pregnancy Status and Age

\begin{tabular}{|c|c|c|c|c|c|c|}
\hline \multicolumn{7}{|c|}{ AGE } \\
\hline STATUS & $15-24$ & $25-34$ & $35-44$ & $45-54$ & 55-above & Total \\
\hline HIVP PW & $3(9.7)$ & $21(67.7)$ & $6(19.4)$ & $1(3.2)$ & $0(0)$ & 31 \\
\hline HIVN PW & $49(34.5)$ & $72(50.7)$ & $21(18.8)$ & $0(0)$ & $0(0)$ & 142 \\
\hline HIVP NPW & $9(14.8)$ & $14(23.0)$ & $34(55.7)$ & $3(4.9)$ & $1(1.6)$ & 61 \\
\hline HIVN NPW & $82(30.8)$ & $102(38.3)$ & $51(19.2)$ & $10(3.8)$ & $21(7.9)$ & 266 \\
\hline Total & $143(28.6)$ & $209(41.8)$ & $112(22.4)$ & $14(2.8)$ & $22(4.4)$ & 500 \\
\hline
\end{tabular}

\subsection{Relationship between HIV/pregnancy, marriage type (monogamy/polygamy), settlement, occupation and Education status}

Table 4 shows the relationship between HIV/pregnancy status and marriage type (monogamy/polygamy). 271 of the 500 women were in monogamous marriages while the remaining 229 were in polygamous ones. The least occurrence of the virus in monogamous pregnant women was $3.7 \%$ while it was $9.2 \%$ in polygamous pregnant women; it was $6.6 \%$ in monogamous non-pregnant women and $18.8 \%$ in polygamous non-pregnant women. Thus, the disease occurred significantly more in women in polygamy, whether they were pregnant or not. In the chi square analysis, a strong relationship between type of marriage and HIV/pregnancy status is evident.

Table 4 also shows the relationship between HIV/pregnancy status and occupation of the subjects. Among the pregnant women with HIV, 11.8\% were full-time housewives, 3.6\% business women, and $4.6 \%$ were civil servant. Among the non-pregnant HIV-positive women, 20.47\% were full housewives, $9.9 \%$ business women, and $9.2 \%$ civil servants. It can be seen that in both groups (pregnant and non-pregnant), full housewives were more predisposed to the infection. There was a significant $(\chi 2=25.73, \mathrm{p}=0.000)$ relationship between HIV/pregnancy status and the type of occupation.

Relating the occurrence of HIV to the type of settlement of the subjects, it was found that the least occurrence of viruspositive pregnant women from urban centers was $6.9 \%$ while from rural centers was $4.3 \%$; while for the negative non-pregnant women, urbans and rurals were and 51.1\% and 58.6\% respectively. Of women who are HIV-positive but not pregnant, $13.6 \%$ were from the rural areas and $11.7 \%$ from urban areas. Statistical analysis showed that there was no significant $(\chi 2=4.10, \mathrm{p}=0.251)$ relationship between HIV/pregnancy status and location.

Taking occupation into consideration, full house wife had the greatest occurrence of HIV positive in both pregnant and non-pregnant groups: HPPW and HPNPW 15 (36.65\%) and $26(63.4 \%)$ in HPPW and HPNPW respectively. Business class women on the other hand had $4(26.7 \%)$ HPPW and 11(73.3\%) HPNPW. 
The distribution of infected and uninfected pregnant and non-pregnant women according to education status is given in Table 4. The data showed that only 93 were illiterate of the 500, hence 407 were literate. Of the HIV-positive pregnant women, $7.1 \%$ were literates while $2.2 \%$ were illeterates. Of the positive but not pregnant, $12 \%$ were literate while $12.9 \%$ were illiterate. A significant $(\chi 2=32.52, \mathrm{p}=0.000)$ relationship between HIV/pregnancy status and educational status was observed from the chi-squared analysis. There was significant difference $(p<0.05)$ between HIV seropositivity and educational status. The literates had the highest prevalence of the virus.

Table 4 Relationship between HIV/Pregnancy Status and Other Factors

\begin{tabular}{|c|c|c|c|c|c|c|}
\hline \multicolumn{7}{|c|}{ HIV/pregnancy STATUS } \\
\hline & HIV PPW & HIV NPW & PNPW & HIV NNPW & Total & $\chi 2(p$-value) \\
\hline \multicolumn{7}{|l|}{ MARRIAGE } \\
\hline Monogamy & $10(3.7)$ & $84(31.0)$ & $18(6.6)$ & $159(58.7)$ & 271 & \\
\hline Polygamy & $21(9.2)$ & $58(25.3)$ & $43(18.8)$ & $107(46.7)$ & 229 & $25.73(0.000)$ \\
\hline Total & $31(6.2)$ & $142(28.4)$ & $61(12.2)$ & $266(53.2)$ & 500 & \\
\hline \multicolumn{7}{|l|}{ OCCUPATION } \\
\hline Civil Servant & $12(4.6)$ & $74(28.2)$ & $24(9.2)$ & $152(58.0)$ & 262 & \\
\hline Business & $4(3.6)$ & $38(34.2)$ & $11(9.9)$ & $58(52.3)$ & 111 & $25.73(0.000)$ \\
\hline Full House Wife & $15(11.8)$ & $30(23.7)$ & $26(20.47)$ & $56(44.1)$ & 127 & \\
\hline Total & $31(7.0)$ & $142(28.4)$ & $61(12.2)$ & $266(53.2)$ & 500 & \\
\hline \multicolumn{7}{|l|}{ LOCATION } \\
\hline Rural & $6(4.3)$ & $33(23.6)$ & $19(13.6)$ & $82(58.6)$ & 140 & \\
\hline Urban & $25(6.9)$ & $109(30.3)$ & $42(11.7)$ & $184(51.1)$ & 360 & $4.10(0.251)$ \\
\hline Total & $31(6.2)$ & $142(28.4)$ & $61(12.2)$ & $266(53.2)$ & 500 & \\
\hline \multicolumn{7}{|l|}{ EDUCATION } \\
\hline Literate & $29(7.1)$ & $136(33.4)$ & $49(12.0)$ & $193(47.4)$ & 407 & \\
\hline Illiterate & $2(2.2)$ & $8(8.6)$ & $12(12.9)$ & $71(76.3)$ & 93 & $32.52(0.000)$ \\
\hline Total & $31(6.2)$ & $144(28.4)$ & $61(12.2)$ & $264(53.0)$ & 500 & \\
\hline
\end{tabular}

\section{Discussion}

The $18.4 \%$ prevalence observed in this study (Table 1) is higher than the $12.1 \%$ reported for similar studies for Uyo, Akwa Ibom Nigeria, by Etok et al. [9]. The authors sampled women registered for antenatal clinic at St. Luke's Hospital, Aura - Uyo. An even lower prevalence $5.93 \%$ was reported by Obi et al. [10] who carried out similar study on pregnant women participating in antenatal clinics in Port Harcourt, Nigeria. These (other) states are places where non-governmental organizations and the state government have invested time, energy and resources heavily in HIV counseling and testing, therefore the lower prevalence. United State Agency in Development (USAID), Friends in Global Health (FGH), and Management Scientist for Health (MSH) have all exerted eradicative pressures on the virus between 1999 and 2015, explaining the reduced prevalence of the disease. Results higher than of the present study has however been reported in other parts of the country, for example in Kaduna. Edet et al. [11] reported a $55.33 \%$ prevalence among women resident in Kaduna South, North Western Nigeria.

The age brackets of 25-34 and 35-44 were implicated in this study (Table 3) for highest occurrence of HIV infection. This is in agreement with the 31-45 years bracket reported by Akinjogunla and Adegoke [12] and 25-34years bracket reported for a study done in Malawi in 1994. This is also in agreement with UNAIDS's 2016 report that almost half of the more than 36million people living with HIV infection are women of reproductive age. The present study showed that there is very little occurrence of the infection among older women (> 55years), while Edet et al. [11] reported 
highest prevalence was within the $\geq 40$ age range. Most other studies like the aforementioned authors agree that younger women are more infected. Sexual activity may be one factor behind the data above: older women are as a matter of fact less sexually active while the younger ones are much more sexually active and also independent of their choices, hence higher prevalence among the younger since HIV is largely sexually transmitted.

The result shown for business class women in Table 4 is contrary to the business class' 31 (20.67\%) reported by Edet et al. [11] where they (business women) had the highest occurrence. This may attributable to sexual violence, the little or no power held by women over decisions about sex, and polygamy. Perhaps the biggest issue around HIV/AIDS is the stigma associated, the fear to get tested, thus the lack of awareness of the persons living with it that they are infected. HIV is multi-systemic, and it suppresses the hematopoietic system [13], killing the patient silently as it develops into AIDS.

Furthermore, from table 4 , the significant difference $(\mathrm{p}<0.05)$ between HIV seropositivity and educational status, agrees with Frank-Peterside et al.'s [14] study in Port Harcourt. The literates had the highest prevalence of the virus. This is attributable to the educated people's 'free' social life. [15] However reported to the contrary, finding no significant difference between educational status and HIV seropositivity.

\section{Conclusion}

This study has established that the prevalence of HIV among women in Minna was 18.4\%. The highest prevalence was found in non-pregnant women, literates, full housewives, women in polygamous marriages, and younger people when taking pregancy, education status, occupation, marriage type, and age into cognizance respectively. The study thus showed that there was significant association between HIV infection and these other factors respectively. The relatively high prevalence makes it pertinent that government and non-governmental organizations step into the scene to curb the trend by increasing their effort in public education and legislature.

\section{Compliance with ethical standards}

\section{Acknowledgments}

The authors would like to acknowledge the research ethics and publication committee of all the sampled hospitals and also the HOD, laboratory department of Dr Musa Inuwa Hospital for his technical inputs. This research did not receive any specific grant from funding agencies in the public, commercial, or not-for-profit sectors.

\section{Disclosure of conflict of interest}

There was no conflict of interest among the authors.

\section{Statement of ethical approval}

All procedures performed in this study involving human participants were in accordance with the ethical standards of the Federal University of Technology, Minna Committee on Ethics for Medical and Scientific Research and with the 1964 Helsinki declaration and its later amendments or comparable ethical standards.

\section{Statement of informed consent}

Informed consent was obtained from all individual participants included in the study.

\section{References}

[1] World Health Organization Fact Sheet. (2014). World Health Organization Fact Sheet Global Update on the Health Sector Response to HIV. Geneva, Switzerland.

[2] UNAID (2016). Global AID updates Joint United Nations Programme on HIV/AIDS. Geneva, Switzerland unaids.org

[3] Centers for Disease Control (CDC). (2012). Recommendations for prevention of HIV transmission in health-care settings. Morbidity and Mortality Weekly Report, 36 (2), 1-18. 
[4] Douek DC, Roederer M and Koup RA. (2009). Emerging Concepts in the Immunopathogenesis of AIDS. Annual Revision Medicine, 60, 471-484.

[5] Minkoff HL, Willoughby A and Mendez H. (1990). Serious infections during pregnancy among women with advanced human immunodeficiency virus infection. American Journal Obstetical Gynecology, 162, 30-34.

[6] Niger State Bureau of Statistics. (2016). Facts and Figures of Niger State. Printed under the auspices of Nigeria Statistical Development Project (NSDP).

[7] Kuta FA, Audu SL, Garba SA, Abdusalam R and Abadara NU. (2016). Prevalence and Antibiotics susceptibility profile of Helicobacter pylori Isolated from outdoor patients presenting signs of ulcerative colitis in three Hospitals in Niger state, Nigeria.

[8] WHO. (2010). WHO guidelines on drawing blood: best practices in phlebotomy. Publications of the World Health Organization Press, World Health Organization, 20 Avenue Appia, 1211 Geneva 27, Switzerland.

[9] Etok CA, Etukafia MI and Mboto CI. (2010). Seroprevalence of Human Immunodeficiency Virus (HIV) infection among antenatal clinic attendees in St. Luke's Hospital, Uyo, Akwa-Ibom State Nigeria. Global Journal of Pure and Applied Sceinces, 16(2), 189-193.

[10] Obi RK, Iroagba II. \& Oriako OA. (2007). Prevalence of Human Immunodeficiency Virus (HIV) infection among pregnant women in an antenatal clinic in Port-Harcourt, Nigeria. African Journal of Biotechnology, 6 (3), 263 266.

[11] Edet UO, Ebana RUB, Etok CA and Nwamuo LC. (2016). Prevalence of Human Immunodeficiency Vims and Plasmodium Falciparium. Dual infection amongst residents of Kaduna South in North Western Nigeria. International Journal of Disease and Health, 17(1), 1 -7.

[12] Akinjogunla OJ and Adegoke AA. (2009). Seroprevalence of human immunodeficiency virus (HIV) 1 and 2 infections in Uyo metropolis. Akwa-Ibom State Scientific Research and Essay, 4(11), 1281 - 1384.

[13] Obeagu EI, Okoroiwu IL, Ochei KC, Okoro NK and Udenze CL. (2014). CD4 count of ART and Non-ART HIV positive patients attending Living Word Mission Hospital Abayi Aba, Abia State, Nigeria.

[14] Frank-Peterside N, Okonko IO, Okerentugba PO and Jaja N. (2012). Detection of HIV 1 and 2 antibodies among pregnant women in Port Harcourt, Rivers State, Nigeria. World Applied Science Journal, 16(4), 589-598.

[15] Okerentugba PO, Uchendu SC, Okonko 10. (2015). Prevalence of HIV among pregnant women in Rumubiakani, Port Harcourt, Nigeria. Public Health Research, 5(2), 58 - 65.

\section{How to cite this article}

Adeoye RA, Garba SA, Galadima M, Ossamulu IF and Ariyeloye SD. (2019). Prevalence of HIV among women attending selected hospitals in Minna, Niger state, Nigeria. GSC Biological and Pharmaceutical Sciences, 9(1), 70-76. 